\title{
Non-syndromic pontocerebellar hypoplasia
}

INSERM

\section{Source}

INSERM. (1999). Orphanet: an online rare disease and orphan drug data base. Nonsyndromic pontocerebellar hypoplasia. ORPHA:98523

Nonsyndromic pontocerebellar hypoplasias $(\mathrm{PCH})$ are a rare heterogeneous group of diseases characterized by hypoplasia and atrophy and/or early neurodegeneration of the cerebellum and pons. Eight subtypes named type 1-8 have been described (see these terms), generally inherited in an autosomal recessive pattern. 